\section{Community College Instructors' Perceptions of Constraints and Affordances Related to Teaching Quantitative Biology Skills and Concepts}

\author{
Lisa A. Corwin, ${ }^{\dagger}$ Stacey Kiser, ${ }^{\ddagger}$ Sondra M. LoRe, ${ }^{\S}$ Jillian M. Miller", and \\ Melissa L. Aikens ${ }^{\text {T* }}$ \\ 'Department of Ecology and Evolutionary Biology, University of Colorado, Boulder, Boulder, \\ CO 80309; ' Science Division, Lane Community College, Eugene, OR 97405; \$National Institute for \\ STEM Evaluation and Research, University of Tennessee, Knoxville, TN 37996; "Mathematics and \\ Sciences Division, Roane State Community College, Harriman, TN 37748; 'Department of \\ Biological Sciences, University of New Hampshire, Durham, NH 03824
}

\begin{abstract}
Quantitative skills are an important competency for undergraduate biology students and should be incorporated early and frequently in an undergraduate's career. Community colleges (CCs) are responsible for teaching introductory biology to a large proportion of biology and prehealth students, and quantitative skills are critical for their careers. However, we know little about the challenges and affordances that CC instructors encounter when incorporating quantitative skills into their courses. To explore this, we interviewed CC biology instructors $(n=20)$ about incorporating quantitative biology (QB) instruction into their classes. We used a purposeful sampling approach to recruit instructors who were likely to have tried evidence-based pedagogies and were likely aware of the importance of QB instruction. We used open coding to identify themes related to the affordances to and constraints on teaching QB. Overall, our study participants met with challenges typical of incorporating new material or techniques into any college-level class, including perceptions of student deficits, tension between time to teach quantitative skills and cover biology content, and gaps in teacher professional knowledge (e.g., content and pedagogical content knowledge). We analyze these challenges and offer potential solutions and recommendations for professional development to support QB instruction at CCs.
\end{abstract}

\section{INTRODUCTION}

Quantitative skills, such as the ability to perform basic algebraic calculations, reason with numbers, interpret graphical representations, use and interpret basic statistics, and use and create models, are an important competency for biology students emphasized by BIO2010 (National Research Council, 2003) and Vision and Change (American Association for the Advancement of Science, 2011). These skills are integral for conducting scientific investigations, communicating important findings, and interpreting scientific results. Moreover, they are increasingly in demand with the rise in prominence of fields such as biotechnology, bioinformatics, and data science. To ensure biology students master quantitative skills, it is argued that such skills should be incorporated into all biology courses (Feser et al., 2013).

However, incorporating quantitative skills into biology courses can be challenging for instructors. Instructors must find time to create or adapt existing quantitative biology (QB) curricula, and investing in these activities must be rewarded in the promotion and tenure process (Marsteller et al., 2010). Instructors may also be unsure of how to fit quantitative skills into a course that is already packed with biology concepts (Bray Speth et al., 2010). An additional challenge arises when instructors' expectations of
Kimberly Tanner, Monitoring Editor Submitted Jan 7, 2019; Revised Sep 23, 2019; Accepted Oct 2, 2019

CBE Life Sci Educ December 1, 2019 18:ar64 DOI:10.1187/cbe.19-01-0003

*Address correspondence to: Melissa L. Aikens (melissa.aikens@unh.edu).

(c) 2019 L. A. Corwin et al. CBE-Life Sciences Education () 2019 The American Society for Cell Biology. This article is distributed by The American Society for Cell Biology under license from the author(s). It is available to the public under an Attribution-Noncommercial-Share Alike 3.0 Unported Creative Commons License (http://creativecommons.org/licenses/ by-nc-sa/3.0).

"ASCB $®$ " and "The American Society for Cell Biology $\otimes^{\prime \prime}$ are registered trademarks of The American Society for Cell Biology. 
students' math preparation or math interest are misaligned with students' background experiences, necessitating further curricular adaptation. Yet, despite these challenges, a number of QB curricular innovations have been developed and implemented, leading to improved student attitudes and performance on quantitative tasks (Bray Speth et al., 2010; Thompson et al., 2010; Colon-Berlingeri and Burrowes, 2011; Goldstein and Flynn, 2011; Madlung et al., 2011; Hester et al., 2014; Hoffman et al., 2016; Zagallo et al., 2016; Olimpo et al., 2018). However, research on the implementation of quantitative curricula has largely focused on 4-year institutional settings. Despite the importance of community colleges (CCs) in postsecondary education, we have little understanding of the landscape of QB instruction at these institutions.

CCs and CC instructors make a significant contribution to the training of life science students nationwide. Here, we define a $\mathrm{CC}$ as a nonresidential junior college offering primarily 2-year degrees to people living in a particular area. CCs enrolled more than 7 million students in 2015, or $40 \%$ of undergraduates (National Science Board, 2018), and enrollment at CCs is projected to increase by 12\% through 2027 (McFarland et al., 2018). Nearly half of undergraduates who complete a bachelor's degree attend a CC at some point in their educational careers (American Association of Community Colleges, 2019). Moreover, CCs enroll the majority of Latinx and Native American students and nearly half of all Black and Pacific Islander undergraduates, as well as a substantial number of first-generation college and low socioeconomic status students (American Association of Community Colleges, 2019). Thus, they play a critical role in increasing access to science, technology, engineering, and mathematics (STEM) disciplines for underserved groups.

Despite the vast number of students served by these institutions, evidence suggests that less than $4 \%$ of biology education research has been conducted with the intention of understanding teaching and learning at CCs (Schinske et al., 2017; Lo et al., 2019). This is concerning, considering that we will be unable to fully understand QB instruction in the United States if we do not investigate the contexts that serve nearly half of all STEM majors. Furthermore, QB instruction is critical at CCs, because many students are seeking occupational degrees that necessitate quantitative skills, such as those in the health sciences or biotechnology fields. Health sciences is the most commonly pursued career and technical education degree (36\% of subbaccalaureate students in career and technical education fields) and has grown faster than any other technical education program (U.S. Department of Education, Office of Planning, Evaluation and Policy Development, Policy and Program Studies Service, 2014; Zhang and Oymak, 2018). As an example, associate's degrees in nursing, offered primarily via CCs, provide almost $60 \%$ of entry-level nurses each year and attract more minority participants than baccalaureate programs (Mahaffey, 2002). Several studies have documented poor numeracy skills among nurses (Jukes and Gilchrist, 2006; Eastwood et al., 2011), despite the importance of mathematics to their profession, particularly for drug calculations. Biotechnology certificate programs, designed for workforce development, are also growing at CCs. Biotechnology draws heavily on chemistry, molecular biology, and microbiology, all of which use quantitative skills. There have been calls to integrate Vision and Change core competencies, including quantitative reasoning, into CC biology classes (e.g., Dolan, 2012); yet only recently have efforts been reported on the design (e.g., Gonzalez, 2016) and assessment (BrancaccioTaras et al., 2016; Peteroy-Kelly et al., 2019) of quantitative reasoning instruction in biology courses at CCs.

Because of the institutional and pedagogical culture and demographics of CCs, CC instructors may encounter unique challenges of and affordances to teaching quantitative skills. For example, a challenge that may be particularly germane for CC instructors is coping with low math self-efficacy and high math anxiety among biology students. Fifty-nine percent of students attending public 2-year institutions are enrolled in developmental math courses because their preparation is deemed insufficient by their institutions (as a point of comparison, 33\% of students at public 4-year institutions are enrolled in a developmental math course; Chen, 2016), and high school math preparation has been shown to be correlated to students' math self-efficacy and math anxiety (Pajares and Miller, 1994; Andrews and Aikens, 2018). Additionally, CCs have high numbers of nontraditional students (students older than 25; Paulson and Boeke, 2006; McFarland et al., 2018) who are more likely to lack confidence in their academic abilities (Ross-Gordon, 2003). They often experience lower math self-efficacy and higher math anxiety than traditional students owing to the time that has passed since they last took a math course (Betz, 1978; Jameson and Fusco, 2014). Alternatively, the CC context may also facilitate unique affordances to teaching QB that could serve to inform QB instruction more broadly. Only by studying the experiences of those within the CC context can we begin to document the challenges and affordances that CC instructors encounter, a critical step for informing the design of professional development (PD) that can effectively serve CC instructors and potentially those beyond CC contexts (National Research Council and National Academy of Engineering, 2012).

This exploratory study aimed to take a first step in elucidating gaps in knowledge that exist surrounding the constraints on and affordances to QB instruction at CCs and how we might best incentivize PD for biology instructors who wish to incorporate quantitative skills into their curricula. In particular, we wanted to know 1) What factors provide CC instructors opportunities to teach QB in their biology courses or aid the inclusion of QB approaches? 2) What factors hinder CC instructors' ability to integrate QB into their courses? 3) What factors serve as incentives and/or facilitate CC instructor participation in QB PD? To answer these questions, we conducted semistructured interviews with CC biology instructors who were knowledgeable about undergraduate education reform efforts, such as calls for incorporating more QB into curricula. This preliminary investigation will inform broader efforts to survey instructors nationally and begin iterative design of QB PD for CC instructors.

\section{METHODS}

This study was conducted with approval from the Internal Review Board for Human Subjects at the University of Colorado, Boulder (\#17-0326).

\section{Study Participants}

Study participants consisted of 20 CC instructors who were actively engaged in either biology education research communities or QB education communities (Table 1). Using a purposeful sampling approach (Emmel, 2013), we specifically recruited 
TABLE 1. Demographics of faculty participants

\begin{tabular}{|c|c|c|c|c|c|c|}
\hline Pseudonym & Gender & Race & Full- or part-time & Years teaching & $\begin{array}{c}\text { Attended an education } \\
\text { conference or an education } \\
\text { section in the last } 3 \text { years }\end{array}$ & $\begin{array}{l}\text { Attended a } \\
\text { QB training or } \\
\text { conference }\end{array}$ \\
\hline Tom & M & White & FT & $>10$ & Yes & Yes \\
\hline Mary Beth & $\mathrm{F}$ & White & FT & $>10$ & Yes & No \\
\hline Sandy & $\mathrm{F}$ & White & FT & $>10$ & Yes & No \\
\hline Julie & $\mathrm{F}$ & White & FT & $>10$ & Yes & Yes \\
\hline Cindy & $\mathrm{F}$ & White & FT & $>10$ & Yes & Yes \\
\hline Dave & M & White & FT & $>10$ & Yes & Yes \\
\hline Sunny & $\mathrm{F}$ & White & PT & $5-10$ & Yes & No \\
\hline Kathy & $\mathrm{F}$ & White & FT & $>10$ & Yes & Yes \\
\hline Vicky & $\mathrm{F}$ & White & FT & $>10$ & Yes & Yes \\
\hline Hugh & M & White & FT & $>10$ & No response & No response \\
\hline Ana & $\mathrm{F}$ & White & FT & $<5$ & No & Yes \\
\hline Mikaela & $\mathrm{F}$ & White & FT & $>10$ & Yes & Yes \\
\hline Debbie & $\mathrm{F}$ & White & FT & $5-10$ & Yes & Yes \\
\hline Linda & $\mathrm{F}$ & White & $\mathrm{FT}$ & $5-10$ & No response & No \\
\hline Brianna & $\mathrm{F}$ & White & PT & $>10$ & Yes & No \\
\hline Curt & M & White & $\mathrm{PT}$ & $<5$ & No & Yes \\
\hline Edith & $\mathrm{F}$ & White & FT & $>10$ & Yes & No \\
\hline Gwen & $\mathrm{F}$ & White & FT & $>10$ & Yes & Yes \\
\hline Ronnie & $\mathrm{F}$ & White & FT & $>10$ & Yes & Yes \\
\hline Cam & M & Nonwhite & FT & $5-10$ & Yes & Yes \\
\hline
\end{tabular}

instructors from these two communities, because we were looking for individuals who were 1) thoughtful about their own teaching, 2) likely to have tried to integrate evidence-based pedagogies into their teaching, and 3) likely to be aware of the importance of incorporating quantitative skills and concepts into biology (i.e., aware of Vision and Change and/or BIO2010 competencies). Specifically, we recruited instructors who attended the following conferences or workshops in 2017: the Society for the Advancement of Biology Education Research Annual Conference, the Gordon Research Conference on Undergraduate Biology Education Research, BioQUEST Curriculum Consortium, and CC-BIOME (Community College Biology Master Educators). Our recruitment procedures consisted of first identifying CC instructors attending each conference by searching the publicly available attendee lists for each conference. This resulted in a total of 32 invitations being sent to potential participants, of whom 14 agreed to be interviewed (43\%). We then sent an invitation to the CC membership of the National Association of Biology Teachers (NABT) via the NABT Facebook page. This invitation had potential to reach 600 CC instructors who could visit this page, although we have no way to confirm how many viewed the invitation. We recruited another six participants via this invitation. This recruitment design allowed us to specifically recruit from pools of individuals enriched in the characteristics we described (points 1-3).

Our final list of participants represented the populations from which we were recruiting and consisted of full-time instructors and part-time instructors (Table 1). Compared with national faculty numbers, this group overrepresents full-time instructors (full-time instructors represent one-third of all CC instructors nationally; McFarland et al., 2018), due to our constraints on interviewing instructors who attended education conferences. Thus, we were careful to draw attention to parttime instructor comments in our results (see quotes from Curt,
Brianna, and Sunny). This group also overrepresents women (75\% in our sample compared with $50 \%$ of CC instructors nationally; McFarland et al., 2018). Finally, the sample overrepresents white individuals (95\% in our sample compared with $85 \%$ of CC instructors nationally; McFarland et al., 2018). Although we have no specific hypotheses as to how gender or race might alter our results, we must consider this a limitation of our sample. Our participants came from institutions representing various levels of diversity, including six institutions serving greater than $50 \%$ minority students, nine serving greater than $25 \%$ minority students, and five with minority enrollment under 25\% (minority enrollment determined by Community College Review [CCR], 2019). Participants also represented both urban and rural schools, with eight hailing from urban campuses, seven from suburban campuses, and five from rural campuses (CCR, 2019). Geographically, our participants were diverse and represented colleges in both the northern and southern regions of coastal western states, interior western states, midwestern states, and eastern states. In total, 15 U.S. states were represented in our sample.

In semistructured interviews lasting 40-70 min, participants described their experiences teaching QB at CCs, their perceptions of the affordances to and challenges of teaching $\mathrm{QB}$ at their institutions, and their thoughts on what would motivate CC instructors (including themselves) to attend PD targeting QB instruction (Supplement 1 in the Supplemental Material). Interviews were audiotaped and transcribed.

An exploratory-hermeneutic phenomenological approach, which explores transcribed text for patterns related to a specific phenomenon, was used for analysis (Sloan and Bowe, 2014). We (the coders, M.L.A., L.A.C., S.K., S.M.L., J.M.M.) aimed to temporarily set aside prior knowledge of the phenomena under study-QB instruction and PD—-to explore the phenomena with a fresh perspective, allowing inductive interpretations to 
emerge. We used inductive coding to determine codes present within the data (Saldaña, 2016) and started by generating codes in three broad categories: constraints on teaching QB, affordances to teaching $\mathrm{QB}$, and incentives to attend $\mathrm{PD}$ for $\mathrm{QB}$. To establish codes, three coders (M.L.A., L.A.C., S.K.) read the data in their entirety to get a sense of participants' experiences and thoughts. These three members then jointly coded three transcripts to establish a preliminary codebook and come to consensus on code descriptions. After establishing the codebook, M.L.A. and L.A.C. (group 1) coded 50\% of the interviews, while S.K., S.M.L., and J.M.M. (group 2) coded the other $50 \%$. Group members coded independently and then came together to reach consensus within their groups.

After each group coded a set of interviews, $30 \%$ of the coded quotes for each code category (i.e., for constraints, affordances, and incentives) were coded by the other group (i.e., group 1 provided $30 \%$ of their coded quotes to group 2 and vice versa) to measure interrater reliability. Because coding for the different categories was conducted separately for each category, it was appropriate to calculate interrater reliability separately for each of the three categories. Interrater reliability, calculated as Cohen's kappa, was calculated at 0.886 for constraints, 0.885 for affordances, and 0.831 for incentives. Discrepancies between the two coding groups were resolved with discussion.

After final coding and resolution of discrepancies, we quantified the total number of participants reporting each code (Figures 1 and 2 and Supplemental Figure 1). We then identified major themes in the data based on the frequency of code appearance and similarities between codes. Representative quotes were chosen for each code (Supplemental Tables 1-3 and Results). Quotes were lightly edited for confidentiality and clarity, for example, we added brackets to replace names with pseudonyms or pronouns, and then checked to confirm that they retained their original meaning.

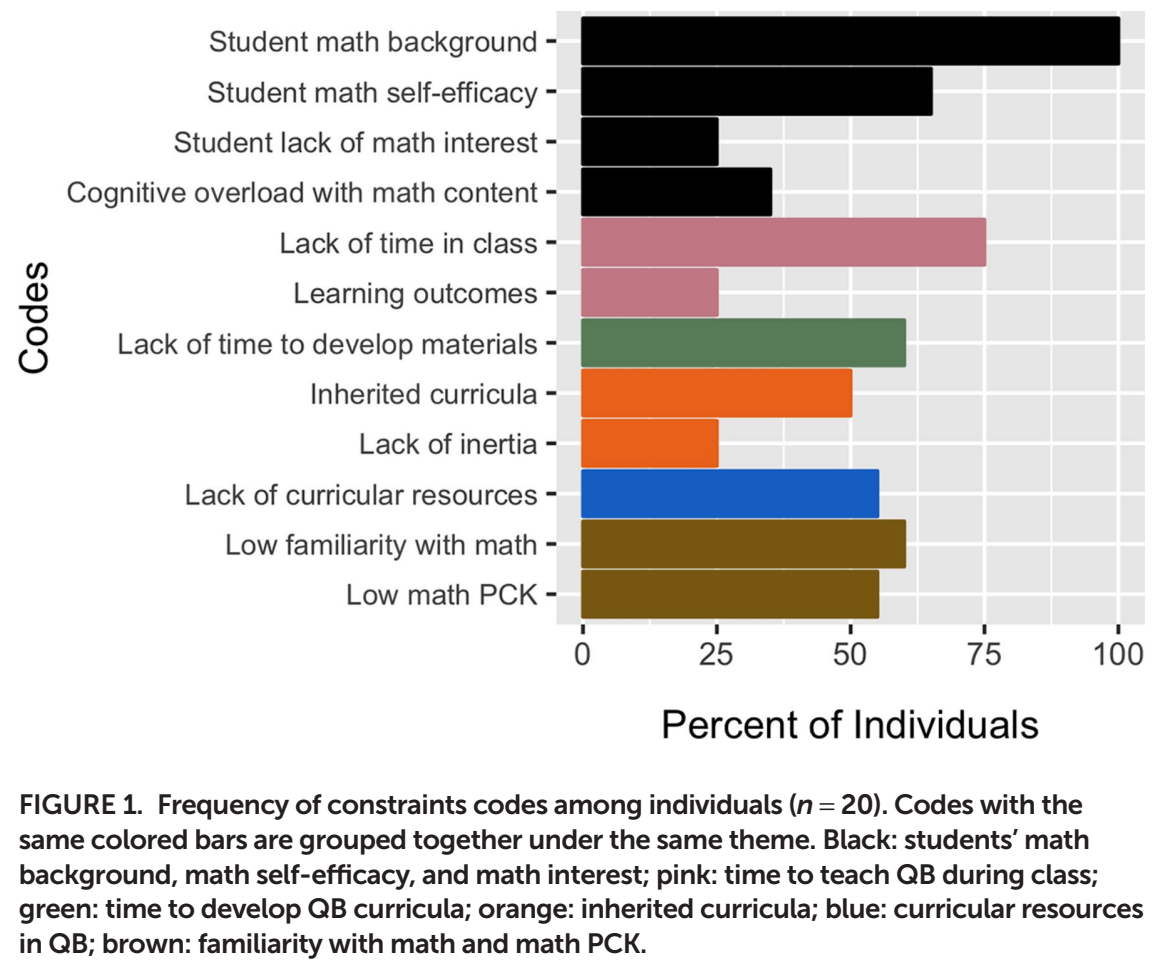

\section{Trustworthiness and Positionality}

To increase the trustworthiness of our data, we derived codes independently before cross-checking with other team members, checked transcripts against audio files when meaning was unclear, provided examples in the codebook, and discussed the major themes among all researchers to ensure interpretation of themes was consistent. As researchers, our identities and professional aims may influence how we view and interpret the data. Two of us (S.K. and J.M.M.) are CC faculty who teach QB subjects. Three of us (S.K., L.A.C., and J.M.M.) are actively involved in initiatives offering PD to CC instructors. One of us (M.L.A.) actively studies integration of QB into biology curricula. All of us are members of a national group dedicated to the improvement of QB instruction at CCs (QuantBio at Community Colleges Working Group at the National Institute for Mathematical and Biological Synthesis [NIMBioS]). We strive for consistency and trustworthiness in our data with the goal of accurately reflecting participants' responses.

\section{Limitations}

As with any study, certain aspects of the work limit what can be inferred from the findings. First, our sample is subject to selection bias. Though we recruited instructors from a variety of institutions within our designated sampling group, it is likely that instructors who were either more interested in the topic of the study or who felt greater social pressure to contribute to this research opted in. Given this, our sample was enriched for individuals who were particularly interested in QB before the study (Table 1).

Likewise, our goal of specifically characterizing affordances and constraints encountered by instructors who were 1) thoughtful about their own teaching, 2) likely to have tried to integrate evidence-based pedagogies into their teaching, and 3) likely to be aware of the importance of QB necessarily limited our sample. Specifically, our sample consists only of instructors who attended an educational conference and/ or QB workshop in the last 3 years (Table 1). Instructors outside our sample may encounter different challenges or affordances than we report here. Thus, we cannot extrapolate our results to all CC instructors. However, the power of our sample lies in that the individuals interviewed were highly likely to have already attempted to integrate new innovations into their classes and were aware of the importance of QB. Thus, our participants were more likely to have encountered a broader range of affordances to and constraints on QB instruction than a random sample of CC instructors who may or may not have attempted to integrate QB into their curricula. This purposeful sampling approach is likely to add depth and thought to our data and analyses that might not have been possible with a broader, less purposeful sample of instructors for our interviews. Thus, we feel that the benefits of our purposeful sampling 


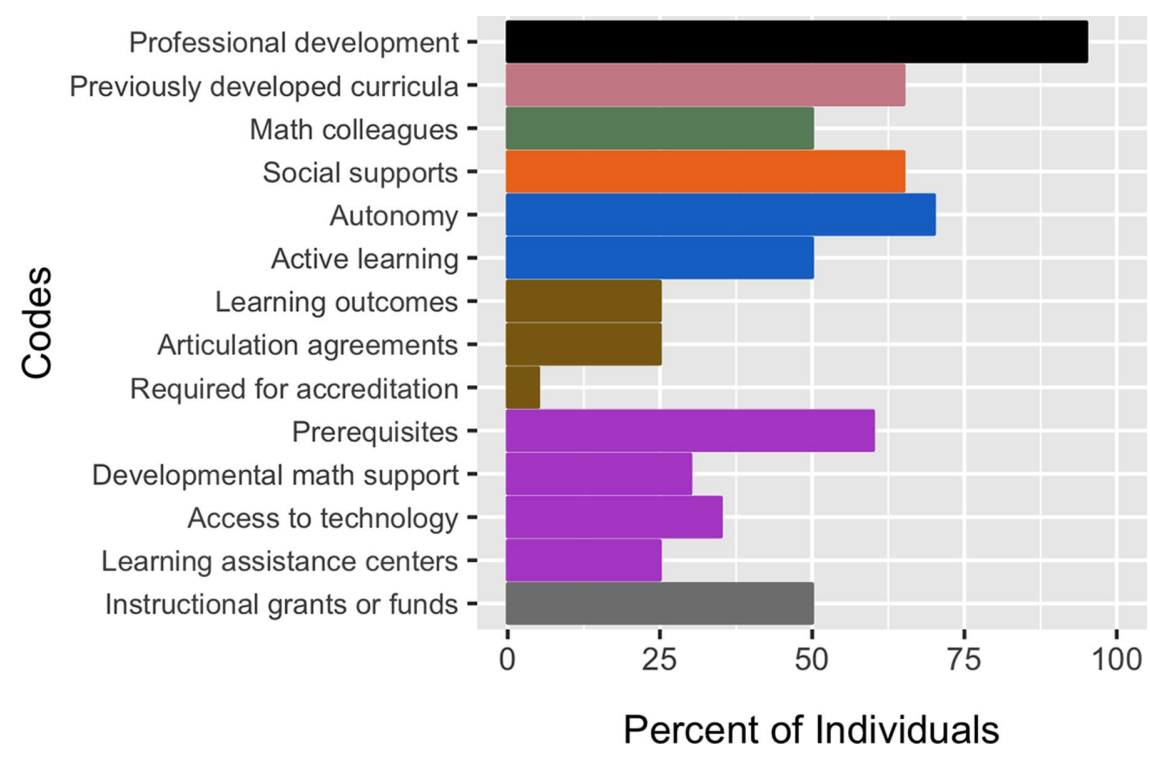

FIGURE 2. Frequency of affordances codes among individuals $(n=20)$. Codes with the same colored bars are grouped together under the same theme. Black: professional development; pink: previously developed curricula; green: math colleagues; orange: social supports; blue: autonomy and active learning; brown: learning outcomes, articulation agreements, and accreditation; purple: student supports; gray: instructional grants or funds.

methods outweigh the costs when gathering data on affordances and constraints.

Limitations due to purposeful sampling and selection bias play out slightly differently when considering data on incentives that motivate instructors to attend QB PD. Instructors in our sample, especially because they are highly likely to be enthusiastic about new teaching innovations, may be more motivated than average to attend professional development. They may report needing fewer or different incentives to attend QB professional development than instructors not included in this study. Thus, additional incentives beyond those reported in this study may be required to attract a broad range of instructors to QB professional development. Nonetheless, our data are valuable, because they uncover what might be considered the "bare minimum" in incentives to attend QB PD. While these data are useful, this limitation is significant. Therefore, we have opted not to include the incentives results and discussion in the main body of the paper. Instead, we include this information in the Supplemental Material for individuals interested in this portion of our results (Supplement 2 in the Supplemental Material).

Finally, the data we collected consist of self-reports from instructors. A drawback of self-reporting is that it represents perceptions of reality that may not always be accurate. For example, it could be that instructors perceive that students are math averse when in fact students are not math averse. Thus, we must consider that our data are entirely viewed through the CC instructors' "lens" (Denzin and Lincoln, 2013); the data do not include other views, such as those from administrators or students. Because we were specifically interested in instructors' perspectives in this study, this is not a large drawback yet it is important to mention because it limits the claims that can be made from these data. Despite these limitations, the data we have collected can be meaningfully interpreted to inform investigations of affordances to and constraints on teaching $\mathrm{QB}$ in CC contexts.

\section{RESULTS}

We discuss here the major categories and themes generated from our codes. The constraints category included limitations to teaching $\mathrm{QB}$ that may ultimately prevent students from learning $\mathrm{QB}$ skills. The affordances category included themes that help instructors to teach QB in their classrooms. We use participants' quotes to draw attention to instances in which participants expressed that a particular affordance could alleviate constraints.

\section{Constraints}

Six major themes emerged within the constraints category (see Supplemental Table 1 for code definitions and examples). Themes constitute between one and four discrete codes.

\section{Students' Math Background, Math Self-Efficacy, and Math Interest}

The four codes that constitute this theme, student math background, student math self-efficacy, student lack of math interest, and cognitive overload with math content, relate to how instructors perceived students' readiness to engage with QB concepts (Figure 1). When considering cognitive factors such as preparation and math knowledge and skills, instructors explained that students might not be "math ready," expressing that students might not have adequate math skills, because they often enter biology courses without prerequisites or up-to-date math training. Often, instructors reported that a single class included students of "different levels" and "various abilities." Some instructors attributed this lack of preparation to the hiatus some CC students take before returning to obtain their degree:

There's no math pre-req[uisite] to get into my course, and [CCs] have a lot of non-traditional students that come back after many years of having formal education ... And so, they often have really hard challenges around remembering the math that they had.-Julie

Instructors' perceptions of students' fear of math and low math self-efficacy was a second challenge. Instructors reported that this was an added barrier to incorporating QB into classes:

Students are afraid of math. That in effect means that if I want to incorporate more math, more quantitation, more working with numbers into my courses, I am always going to deal with that wall, that fear that students have anytime math things come up.-Curt

Encountering the "wall" of student fear could be discouraging for instructors. Likewise, instructors felt that if students did not have a minimum level of math skills and/or feared math, they would lose interest in learning the biological concepts. Other 
instructors reported that students simply were not interested in math, stating that their eyes would "gloss over" when math was introduced. Overall, wide variability in students' math background and self-efficacy was reported as a frustration, especially when it led to increases in the time it took to walk students through quantitative concepts.

\section{Time to Teach QB during Class}

A second theme, lack of time in class, was based on two codes: lack of time in class and learning outcomes (Figure 1). In general, instructors were hesitant to add more to a schedule they perceived to be packed with required content, and they expressed feeling "pressed for time." Some instructors specifically discussed time constraints associated with learning outcomes. They reported that having a set list of learning outcomes that they had to cover, often put in place to meet articulation requirements, fulfill accreditation requirements, or ensure fidelity over a large number of sections, limited them, because they could not fit other objectives into their curricula:

I have a whole list of objectives that have to come across all these processes as well ... A lot of my time in labs, I want them working on research and data. I don't want them looking under microscopes and that's a really big confinement I'm finding especially with assessment and accreditation coming through, where we're bound by these learning outcomes.-Brianna

\section{Time to Develop QB Curricula}

Lack of time to develop materials, based on a single code with the same name (Figure 1), was a serious constraint for many instructors. Following an expression of how little time she had to develop material, Mikaela explained how her heavy teaching load imposed time limitations:

I teach anywhere from 16 to 21,24 h. That's 30 contact hours for me a week because labs are only half time ... I pretty much just teach.—Mikaela

Time limitations were exacerbated for part-time instructors, because they worked other jobs or filled adjunct positions at multiple institutions. Both full-time and part-time instructors recognized that the per-course salary part-time faculty received was insufficient to adequately compensate the time and effort needed to develop new material.

\section{Inherited Curricula}

Because there was little external impetus or time to develop QB materials anew, instructors sometimes found that inertia impeded change. They often relied on previously developed curricular materials in their teaching. Our third theme reflects these codes: inherited curricula and inertia (Figure 1). Instructors discussed how difficult it was to take the initial step to develop new materials because of the extra effort involved (i.e., inertia prevented change):

Sometimes it can be difficult, honestly, from an inertia standpoint. I already have my lecture slides prepared. Why would I want to modify them and make my life hard adding these two things?-Curt
Others felt pressure to stick with existing materials that other faculty used. Notably, the pressure to maintain an existing curriculum was enhanced when multiple sections of a course were taught by adjuncts or across multiple campuses. One adjunct expressed that she had less power to change curricula than a full-time instructor. This may occur in situations where full-time instructors are entrenched in existing practice. She expressed that, in order to change the course, she would have to wait for the older instructors to leave, saying, "I will sit and wait. I am an adjunct" (Brianna).

\section{Curricular Resources in QB}

A prevalent code, lack of curricular resources in QB, served as its own theme (Figure 1). Instructors cited a lack of curricular resources to teach quantitative skills as a serious hindrance:

[QB is] not something that I feel like we see a lot of professional development opportunities on. You see the latest equipment, or the cool lab, or whatever, but you don't see how to incorporate $\mathrm{t}$ tests and chi squared into your curriculum.-Cindy

Several instructors spoke to how quantitative examples and graphs were not often included in biology texts or were of low quality. They compared this with the incorporation of quantitative problems in other fields, recognizing that, in biology specifically, there is a paucity of quantitative problems and examples:

Our textbooks, there's no [math] problems in the back. There's maybe one in each chapter, there's not 30 or 40 like there is in chemistry or calculus or physics, or any other STEM field.-Vicky

This resulted in many instructors feeling like they needed to generate their own problems if they were to teach QB. For instructors with low familiarity with math concepts, this was not feasible.

\section{Familiarity with Math and Math Pedagogical Content Knowledge}

Familiarity and comfort with executing or teaching math skills and concepts consisted of two codes: low familiarity with math and low math pedagogical content knowledge (PCK; Figure 1). PCK includes instructors' knowledge of how to explain or represent particular concepts (i.e., instructional strategies) and their knowledge of students' preconceptions and misconceptions of a particular concept (Shulman, 1986). Both familiarity with math and math PCK were expressed as frequent barriers to teaching quantitative skills. Instructors stated that they had never learned certain skills that they wanted to teach, as expressed by Ana: "I definitely can't teach it because I don't know it myself," or described that the time since they had engaged with specific math concepts limited recall.

Even when instructors felt like they could perform a QB skill or knew a concept, they often expressed uncertainty about how to teach the skill; in other words, they felt they would need additional PCK to successfully teach: 
So I had a hard time explaining how when you ... This is kind of silly, but when you divide by a negative exponent, how it becomes positive. I had a hard time ... I'm like, "It just does!"-Julie

Although they wanted to teach these skills, instructors' jobs did not afford them regular opportunities to practice or learn new skills.

\section{Affordances}

Eight major themes arose from our results and described affordances to teaching QB at CCs (see Supplemental Table 2 for code definitions and examples). Themes constituted between one and four individual codes.

\section{Professional Development}

Professional development was the most frequently reported affordance code for incorporating quantitative skills into courses and serves as its own theme (Figure 2). When asked what types of PD would be or had been helpful, several instructors discussed PD related to refreshing their own quantitative skills. Instructors also specifically mentioned professional development as a way for them to learn new quantitative skills and tools such as "R ... or other statistical programs like SPSS or Python" (Ana) or "bioinformatics tools" (Kathy) that they would then be able to teach to their students.

Instructors also expressed a desire to learn pedagogies that would enhance the teaching of quantitative skills. Several felt ill-equipped to teach mathematical concepts and thought PD could be used to bolster their math PCK. Expanding upon the quote about dividing by negative exponents in the Constraints section, Julie expressed how PD would help her to develop PCK:

\begin{abstract}
And then, I think where I've run into some struggles is that explaining part. Like even though I'm pretty good at explaining lots of things, there were still a few things that I just couldn't explain for the mathematical education perspective, and sort of how to teach that. How can I do better at teaching that, how can I explain it where there's more than one way than just saying, "Oh, it becomes positive." How could I do a better job of explaining it to the students from a mathematical perspective?... That would be good professional development.-Julie
\end{abstract}

Finally, instructors reported that PD workshops that both provided quantitative activities and discussed how to integrate these activities into the biology content of their courses would be valuable. One instructor explained, "A lot of people don't realize that there are a lot of things that they are teaching that have a quantitative component" (Dave). Other instructors acknowledged the connection between quantitative skills and their course content, but were looking for help in how to incorporate the quantitative skills into their curricula. Curt explained that leaving PD with materials that could be used in his classes would be a great help in starting to incorporate more QB:

It would be a workshop. It would be, "Here is how you incorporate this quantitative technique into your class to teach cellular respiration instead of using these classic slides that such and such book provides you." Or something like that. Certainly, I think that would be a professional development type activity that several people would be quite interested in attending. Particularly if those kinds of materials could be made available to you.-Curt

\section{Previously Developed Curricula}

As reflected in the prior quote by Curt, many instructors expressed that they would like more access to developed curricular materials or stated that developed curricula have helped them. One code, previously developed curricula, represents this theme (Figure 2). Instructors emphasized their desire to have resources that were developed specifically for CC contexts and could be easily integrated into their courses. Some instructors found and modified resources on their own, either by using online search engines or relying on known websites that contain educational materials, such as the Howard Hughes Medical Institute (HHMI) BioInteractive or the National Center for Case Study Teaching in Science.

Other instructors obtained quantitative curricula through PD opportunities or through national initiatives. Such responses could have been influenced by our purposeful sampling design, which resulted in many of our participants having attended such PD events (Table 1). For example, instructors who participated in a BioQUEST/QUBES workshop, an HHMI BioInteractive Faculty Mentoring Network (sponsored by QUBES), or the Small World Initiative reported having access to quantitative curricula that they were then able to implement in their courses.

\section{Math Colleagues}

When instructors needed help understanding math concepts or how to teach them, several found that math colleagues at their institution were particularly helpful (one code: math colleagues; Figure 2). Some reported existing relationships with their math department:

So we do have a good partnership with our math department ... They also provide a lot of advice to faculty members that want to know, "How should I teach this topic?" So our math department is really good at outreach and helping faculty.-Cindy

Other instructors discussed their desire to reach out to math colleagues when needed, but had not yet engaged in partnerships or collaborations. Although no one expressed that they had experienced coteaching with a math colleague, two instructor participants expressed interest in interdisciplinary courses and possibly coteaching with math colleagues.

\section{Social Supports}

The theme social supports consisted of only a single code by the same name (Figure 2). Social supports consisted of supports originating from important others that were primarily psychosocial in nature, meaning that they are related to the social factors that encourage changes in individuals' thoughts and behaviors. Colleagues were an important source of social support, and instructors asserted that it was especially helpful to have peers at the same institution who could support one another in QB integration: 
The instructors in biotech and genetics, we're all progressive and on the same page of feasible change and it's fluid. We want to make it as smooth as possible for the students.Mary Beth

This quote emphasizes that Mary Beth's colleagues had a certain mindset that supported change. This was also mentioned in regard to math colleagues specifically. One participant referred to her math colleagues having "growth mindsets" (Vicky), referencing Carol Dweck's work (Dweck, 2006). She emphasized that being in agreement about the idea that students could improve their knowledge through hard work helped develop camaraderie with her math colleagues. Along with this, shared experiences and troubleshooting were important forms of support when incorporating new material. In some cases, QB PD provided this kind of support:

The cool thing about those workshops is that you meet people who are trying to do the same thing, and you stay in touch with those same folks so that when you're trying to put stuff in your classroom you have that support structure that you can talk to them about it.-Dave

\section{Autonomy and Active Learning}

This theme consisted of two codes: autonomy and active learning (Figure 2). Although there was often pressure to cover certain biological concepts, and this sometimes served as a constraint (see earlier discussion), many instructors experienced autonomy regarding teaching decisions in their classrooms (Figure 2). This afforded them opportunities to include quantitative material in their courses. Even instructors who reported the necessity of teaching course-specific learning outcomes discussed flexibility to teach QB:

We are given an outline of what we are expected to cover and then we can go with it [in] any direction we want, as long as we cover those concepts.-Sunny

Notably, however, some instructors discussed that flexibility and autonomy arose only after they were no longer constrained by others' curricula. Even if the expectation of cross-course curricular alignment was not an overt expectation, they still felt pressure to conform to curricular norms. This aligned with the constraint of inherited curricula described earlier.

Instructors who had a reasonable amount of autonomy often chose to incorporate evidence-based pedagogies into their learning in addition to QB skills and concepts (active learning; Figure 2). Several of these instructors mentioned that datadriven labs allowed them to incorporate quantitative skills into their courses. Other instructors mentioned that active-learning pedagogies, such as case studies or team-based learning, were a vehicle for introducing quantitative skills into course content. These instructors expressed that certain active-learning techniques helped them alleviate some of the constraints associated with QB instruction. Specifically, flipping the classroom afforded them more time to teach QB, and incorporating group work helped instructors manage struggling students by allowing more peer-to-peer instruction.

\section{Learning Outcomes, Articulation Agreements, and Accreditation}

When QB skills and concepts were included as part of learning outcomes, articulation agreements, or accreditation requirements, they sometimes acted as an incentive for instructors to include QB in their courses (three codes: learning outcomes, articulation agreements, and required for accreditation; Figure 2):

I think that the incentives [to teach QB] would have to be around articulation agreements ... Because I think it is a challenging thing to do with students and if they [instructors] don't have to, they don't.- Julie

However, some instructors were dubious of the effect that this would have. Sandy expressed that, even when QB skills were explicit components of articulation or accreditation agreements, their inclusion was unlikely to be sufficient to motivate actual curricular change.

\section{Student Supports}

A commonly desired affordance was student supports in QB, and this theme is represented by four codes: prerequisites, developmental math support, access to technology, and learning assistance centers (Figure 2). Instructors reported such supports were helpful when available. These affordances originated from a variety of supports provided at different times during a student's tenure at CC. Support for students to learn math before enrolling in their classes was described as a benefit to their success at QB tasks. These supports took the form of either developmental math courses or specific course prerequisites. However, despite recognizing the benefits of these experiences for students in regard to quantitative skills, instructors also noted that developmental courses and prerequisites could extend time to degree completion, resulting in students becoming discouraged and leaving the program:

[Developmental math courses] can take forever.... Students get so discouraged that they never come back.-Linda

Other supports exist to help students during their time in biology classes. Study rooms and learning assistance centers were reported to be beneficial in providing students with extra help. Tutors, who were usually located within learning assistance centers, also provided supports for students:

We do have excellent math tutors for the students, so that's a nice support system.-Edith

\section{Instructional Grants or Funds}

Funds to support development of new curricula or course release time (one code: instructional grants or funds; Figure 2) was another affordance. Several instructors described funding mechanisms that would allow them to be compensated for the significant time needed to develop new course materials:

If I get the grant money that I applied for from the college, I'm gonna try some course-embedded research experiences with my General Biology I this semester.-Hugh 


\section{DISCUSSION}

Quantitative skills are increasingly important for biology students, yet there are many challenges to incorporating quantitative skills into biology courses. We sought to explore the constraints and affordances that CC instructors perceived when incorporating quantitative skills into biology courses. We focused on CC biology instructors, because 1) they teach a substantial percentage of undergraduates (National Science Board, 2018), and 2) quantitative skills are critical for CC students transferring to 4-year life science degree programs or pursuing careers in the health sciences or biotechnology workforce. We found six themes that served as constraints, hindering CC instructors' ability to integrate QB into their biology courses, and eight themes that served as affordances for incorporating QB into CC biology classes. In the following sections, we draw upon these themes and discuss three major topics that emerged from the constraints: 1) students' math backgrounds and student-deficit models, 2) tensions between time to teach QB and content coverage, and 3) teachers' professional knowledge for QB instruction. We provide a critical analysis and offer solutions based on affordance themes that our CC participants discussed and evidence from the broader literature. Finally, we discuss the implications of our results on designing PD for QB instruction.

\section{Students' Math Backgrounds and Student-Deficit Models}

One of the most commonly cited challenges to incorporating QB into biology courses, according to our participants, was that students were not "math ready" or held a negative view of math. Indeed, CCs serve a significant percentage of students who enroll in developmental math courses (Chen, 2016) or who are nontraditional students (McFarland et al., 2018), which results in a wide range of math backgrounds and attitudes among students in a classroom (Betz, 1978; Hall and Ponton, 2005; Jameson and Fusco, 2014). In such situations, it can be easy to either avoid including QB in the curriculum completely or to include QB with a tacit understanding that students who "lack" an adequate math background may not do well on QB problems. We see this reflected in a quote by Sunny, included under the theme students' math background, math self- efficacy, and math interest: "If they don't have ... an average background in algebra. They may not be able to understand the calculations that were done, and thus I lose them, and they are not as interested in learning the concepts." This view endorses a student-deficit model or the view that students' educational challenges arise from students or their families "lacking some of the academic and cultural resources necessary to succeed" (Smit, 2012) in academic environments. The problem with student-deficit thinking is that it blames students, who are only one component of a complex learning environment (Miller and Tanner, 2015). Such lines of reasoning can reinforce demographic stereotypes, because they transfer contextual disadvantage (e.g., not receiving a high-quality secondary education) into pedagogic disadvantage (e.g., not receiving the support needed to work through prior disadvantage), which can, in turn, be interpreted as differences in ability or motivation for certain demographics (e.g., all CC students not being able to do the skill). This can lead instructors to lower their academic expectations based on students' backgrounds (Ford and Grantham, 2003). Lower expectations and views of student ability as fixed can compromise the educational opportunities offered to students (Smit, 2012) and may lead to greater achievement gaps for different demographic groups (e.g., Canning et al., 2019). Thus, it is clear that deficit views could cause academic problems for CC students.

In taking a critical view of this result, it is important to recognize how widespread this view is among all types of college instructors, and indeed how easy it can be to endorse a student-deficit model. To change this view, we, as instructors at both CCs and 4-year institutions, can reframe deficits as those associated with our teaching or institutions (e.g., course-deficit model; Cotner and Ballen, 2017), which are often tractable targets for change (Smit, 2012). Julie reflects this when she places the responsibility for QB instruction on the institution, rather than the student, stating that changes need to be made via articulation agreements and learning outcomes to further motivate faculty to teach QB (see Julie under Affordances: Learning Outcomes, Articulation Agreements, and Accreditation). Changing the learning environment to promote student learning regardless of student background or attitudes is another tactic than can counter negative effects of student-deficit views. For example, instructors can communicate high expectations, set out achievable goals, and provide appropriate supports for reaching those goals. Julie discussed the way she supports her students while teaching QB by "breaking [the math problems] out on the board into very, very simple steps" to support the learning of nontraditional students who "come back after many years of having [no] formal education." Other participants also described or enacted other student supports that could be leveraged for students' math learning, including learning assistance centers, math resource centers, and changes in their own pedagogy. PD in CC QB instruction that focuses on these shifts may therefore have a positive impact on students.

\section{Tensions between Time to Teach QB and Covering Other Biology Content}

Another challenge commonly cited by the instructors in our study was a lack of time in class to incorporate quantitative skills due to the amount of biology content that needed to be covered. In some cases, the biology content was dictated by required program learning outcomes. Mandatory program learning outcomes are becoming more common at all institution types due to accreditation (Beno, 2004; Nunley et al., 2011). Accreditors expect that institutions document student learning for each outcome; therefore, it becomes important for institutions of higher education to continue to teach and assess these outcomes so that they can retain accreditation. At CCs, these outcomes are often also linked to articulation agreements with 4-year colleges or workforce certificate programs (Beno, 2004), making changes challenging. As described by our participants, there is also pressure to keep curricula and learning outcomes constant over a large number of sections taught by parttime instructors, many of whom are new to the positions each year and benefit from the added structure. Because learning outcomes are kept consistent and frequently assessed, they can serve to encourage instructors to include QB if quantitative outcomes are included, as described in the theme learning outcomes, articulation agreements, and accreditation. Yet, when they are not included, instructors may feel pressure to prioritize other learning outcomes (e.g., Brianna under Time to Teach $Q B$ during Class). 
We feel that it may be valuable to challenge the view held by instructors that there is a lack of available time in class to teach quantitative skills. Instructors do not have to teach quantitative skills at the expense of biology content. Quantitative skills can and should be incorporated in a way that enhances the understanding of specific biology concepts (Bray Speth et al., 2010). They do not need to be an add-on, but rather should complement the biology concepts being taught in class to promote deep biology learning. For example, Hoffman and colleagues (2016) developed quantitative modules around biology topics that they thought could be enhanced by quantitative reasoning, such as Mendelian and population genetics. CC instructors in our study who felt that QB skills enhanced understanding of biology often successfully incorporated quantitative skills into their courses. These instructors identified pedagogical autonomy, that is, freedom in how to teach their content, as an important element allowing them to incorporate QB instruction. For example, one instructor (Ronnie) reported that she was able to incorporate quantitative activities from HHMI that were related to course learning objectives in order to teach quantitative skills. HHMI BioInteractive curricular resources, as well as other online curricular resources such as Data Nuggets, can be sorted and filtered by biology topic, allowing instructors to easily find quantitative activities that align with the concepts being taught. Importantly, studies have found that integration of quantitative skills with biology concepts does not negatively affect gains in biology content knowledge (Barsoum et al., 2013; Hester et al., 2014).

\section{Teachers' Professional Knowledge for QB Instruction}

A teacher's professional knowledge ultimately impacts student learning, and yet, not all instructors have received training in the concepts or skills they are expected to teach or in how to teach these concepts or skills. Our CC biology instructor participants often felt limited in their ability to teach QB by gaps in their math content knowledge and math PCK or knowledge of how to present concepts and ideas so students can learn them (Shulman, 1986). Additionally, some participants identified a lack of QB curricular resources as a constraint. Deep knowledge of a topic, knowledge of how to teach the topic, and knowledge of curricular materials that support learning the topic all contribute to the planning and execution of instruction on that topic (Gess-Newsome, 2015).

The extent to which biology instructors have math content knowledge depends upon their own academic background and training. An instructor's knowledge may depend, for example, on which field of biology he or she studied (e.g., Marshall and Durán, 2018), with some fields receiving more training in specific quantitative skills. Several participants noted that they felt less prepared to teach some math concepts (e.g., statistics) due to their absence of training in that area or the time that had elapsed since they had last used these concepts. This may be particularly relevant to teaching-focused faculty, who are not actively conducting research or other activities that allow them to engage with statistics or modeling. Yet, in some cases, instructors who felt they had sufficient math skills and knew math content still did not feel that they knew how to effectively represent mathematical concepts to students or help struggling students. Together, these findings emphasize that, while acquiring the content knowledge to teach relevant mathematical skills in biology is clearly critical for effective QB instruction, simply having math content knowledge is not enough. PCK, which includes knowledge of how to represent a concept and an understanding of the difficulties students will encounter with the concept (Shulman, 1986), is needed for effective QB instruction.

Participants discussed a variety of means by which they gained math content knowledge and developed PCK to improve their QB instruction. Support from math colleagues was an important avenue through which they could learn quantitative skills and pedagogical methods for teaching mathematical concepts. In our study, instructors found that their math colleagues, who had experience teaching mathematical concepts, had insights into the difficulties students experience with particular math concepts and ways to make those concepts more accessible. Tapping into this "teacher lore" (Ayers and Schubert, 1994) can help to build PCK for quantitative topics. Likewise, PD was often described as helping instructors to improve their content knowledge and broader PCK. Importantly, alleviating constraints associated with participants' familiarity with math and PCK can positively affect instructors' teaching self-efficacy (Park and Oliver, 2008) and influence their likelihood of teaching a concept (Gess-Newsome and Lederman, 2001).

In addition to being able to understand and teach mathematical concepts underlying QB, instructors should have knowledge of and access to a variety of QB curricular resources. Professional knowledge about curricular materials impacts instructional design and, therefore, contributes to the PCK an instructor brings to planning instruction on a particular topic (Gess-Newsome, 2015). Although some participants discussed a lack of QB curricular resources, many QB resources can be found online (see Marsteller et al., 2010, Table 2; Aikens and Dolan, 2014, Table 1). Therefore, it is possible that a lack of dissemination of QB materials, identified as a barrier by Marsteller and colleagues back in 2010, still exists as a barrier today. In addition, there is some evidence that CC instructors have limited access to resources and events where curricular materials might be promoted (Schinske et al., 2017). For example, they often lack sufficient funds to pursue PD, attend conferences, or pay for journal subscriptions. This suggests that more targeted efforts to advertise or distribute QB instructional resources to CC biology instructors may serve as an affordance to CC QB instruction. Access to previously developed QB curricula may also alleviate instructors' concerns about the time it would take to develop QB curricula for their classes.

\section{Implications for PD}

Given our purposeful sampling of CC instructors, it is not surprising that many reported $\mathrm{PD}$ as an affordance to teaching $\mathrm{QB}$. CC instructors who had participated in various forms of QB PD learned new quantitative skills (e.g., bioinformatics, R), became familiar with QB curricular resources, and/or acquired the PCK necessary to teach $\mathrm{QB}$, demonstrating that $\mathrm{PD}$ can address some of the professional knowledge constraints that other instructors identified. PD around QB curricular resources can also be helpful for showing instructors how to integrate quantitative skills with biology concepts, relieving the tension between teaching skills and content. Some participants also highlighted social supports, such as other colleagues attending the PD event, as a component of PD that assisted implementation of QB in the 
classroom. Therefore, we recommend designing PD that facilitates the development of teacher professional knowledge, including content knowledge, curricular knowledge, and PCK, while simultaneously building social supports.

To accomplish this, PD could be composed of workshops that focus on skill development, followed by mentored teaching opportunities that introduce participants to open educational QB resources and coach participants through the adaptation and implementation of a QB module. Mentored teaching, in which a novice is paired with a more experienced teacher, has been shown to be effective at promoting pedagogical change (Henderson et al., 2009). Mentors can help instructors implement new curricula, reflect on the implementation, and enact feedback on the implementation, all of which are important for the development of PCK (Van Driel and Berry, 2012) and critical to affecting change in teaching (Henderson et al., 2011; Ebert-May et al., 2015). Moreover, deliberate mentorship throughout the curricular change process also has the potential to provide social support for QB instruction. Studies of PD specific to CC instructors have described "mentorship" models, in-person meetings, and open communication as being critical components in achieving PD goals, especially for part-time instructors and new CC instructors (Diegel, 2013; Ching and Hursh, 2014; Edwards et al., 2015). One existing PD opportunity that resembles this type of PD is the QUBES Faculty Mentoring Network (FMN). A small group of participants, led by an experienced mentor, meets regularly over the course of a semester to discuss adaptation of an existing QB resource and implementation of the curriculum in class. Given that FMNs are virtual communities that are free to join, this model may be particularly useful for engaging CC instructors, who may have limited travel funds for PD.

While PD could clearly help to resolve many of the constraints faced by faculty, it is not the only route that can be taken. Collegial interactions among instructors can be an important component of social support leading to pedagogical change (Penuel et al., 2012; Andrews and Lemons, 2015; Andrews et al., 2016). Creating local learning communities of biology and math instructors, which can offer social and intellectual support to those interested in trying QB modules in their classes, could be an avenue to explore. Likewise, simply reaching out to a colleague can also help to alleviate constraints, as was demonstrated by participants' interactions with math colleagues.

\section{CONCLUSIONS}

This paper is a first look at the landscape of QB instruction at CCs, which serve a large proportion of students entering fields in the life or health sciences. This first look characterized the challenges of and affordances to teaching QB at CCs through the eyes of instructors actively engaged in the biology education community, and thus likely to have integrated evidence-based pedagogies, including QB instruction, into their classes and to have reflected on their own instruction. This afforded us the opportunity to characterize the phenomenon of attempting to incorporate QB instruction into one's CC class. Overall, we found it somewhat surprising that the vast majority of challenges identified by our CC instructor participants align with challenges typical of incorporating new material or techniques into any college-level class, including student-deficit perceptions, tensions between skill incorporation and content coverage, and gaps in teacher professional knowledge. However, the extent to which instructors at different institution types experience each of these challenges may differ. For example, instructors at institutions with large underserved or nontraditional student populations, which include but are not limited to CCs, may primarily face challenges related to teaching students of diverse academic backgrounds. In contrast, instructors in positions that place a greater emphasis on teaching than research may need to work more actively to refresh knowledge of mathematical concepts and update skills to reflect current research and workforce needs. Our study represents an exploratory qualitative study within a specific context and cannot, therefore, answer questions related to intensity or frequency of challenges across contexts. Future work could compare constraints on and affordances to teaching QB among different types of instructors at different institution types and in different teaching contexts to provide insight into how instructors' experiences differ with regard to challenges. Likewise, additional research is needed to understand the extent to which our results are generalizable to CC faculty more broadly. Overall, we highlight the need for more research to understand instructor motivation and decisions related to QB instruction.

Despite the challenges we found, CC instructors described many affordances that could help overcome these challenges and that could be leveraged across institution types to promote change. These included on-campus infrastructure that would assist both students and instructors during instructional terms, autonomy in their classrooms, and PD to learn math skills and PCK. Given the number of affordances we identified, we are optimistic regarding the potential to enhance QB instruction within CC contexts. We hope that this work will be used to inform future discipline-based education research that could more directly investigate the affordances mentioned here in order to characterize the mechanisms through which they act. For example, future research could collect data directly from students about math self-efficacy and attitudes toward QB topics and quantify how these variables change when QB instructional affordances are provided. We also hope that this work will be used to design, execute, and assess PD that provides CC instructors access to the various supports and affordances reported to facilitate QB instruction.

\section{ACKNOWLEDGMENTS}

This work was conducted as part of the NIMBioS QuantBio@ Community Colleges Working Group, supported by the National Science Foundation through NSF award DBI-1300426, with additional support from the University of Tennessee, Knoxville. We thank the other members of the working group for valuable discussions: Ahrash Bissell, Linda Grisham, Lou Gross, Kristin Jenkins, Vedham Karpakakunjaram, Suzanne Lenhart, Claudia Neuhauser, Christianne Nieuwsma, Tony Weisstein, and Greg Wiggins. We are also grateful to all of the CC faculty who participated in our study. Finally, we thank two anonymous reviewers for their insightful comments.

\section{REFERENCES}

Aikens, M. L., \& Dolan, E. L. (2014). Teaching quantitative biology: Goals, assessments, and resources. Molecular Biology of the Cell, 25(22), $3478-$ 3481 
American Association for the Advancement of Science. (2011). Vision and change in undergraduate biology education: A call to action. Washington, DC.

American Association of Community Colleges. (2019). Fast facts. Retrieved July 6, 2018, from www.aacc.nche.edu/research-trends/fast-facts

Andrews, S. E., \& Aikens, M. L. (2018). Life science majors' math-biology task values relate to student characteristics and predict the likelihood of taking quantitative biology courses. Journal of Microbiology \& Biology Education, 19(2), 1-10.

Andrews, T. C., Conaway, E. P., Zhao, J., \& Dolan, E. L. (2016). Colleagues as change agents: How department networks and opinion leaders influence teaching at a single research university. CBE-Life Sciences Education, 15(2), ar15.

Andrews, T. C., \& Lemons, P. P. (2015). It's personal: Biology instructors prioritize personal evidence over empirical evidence on teaching decisions CBE-Life Sciences Education, 14(1), ar7.

Ayers, W., \& Schubert, W. H. (1994). Teacher lore: Learning about teaching from teachers. In Shanahan, T. (Ed.), Teachers thinking, teachers knowing (pp. 105-121). Urbana, IL: National Conference on Research in English and National Council of Teachers of English.

Barsoum, M. J., Sellers, P. J., Campbell, A. M., Heyer, L. J., \& Paradise, C. J. (2013). Implementing recommendations for introductory biology by writing a new textbook. CBE-Life Sciences Education, 12(1), 106-116.

Beno, B. A. (2004). The role of student learning outcomes in accreditation quality review. New Directions for Community Colleges, 2004(126), 6572.

Betz, N. E. (1978). Prevalence, distribution, and correlates of math anxiety in college students. Journal of Counseling Psychology, 25(5), 441-448.

Brancaccio-Taras, L., Pape-Lindstrom, P., Peteroy-Kelly, M., Aguirre, K. Awong-Taylor, J., Balser, T., ... \& Zhao, J. (2016). The PULSE Vision \& Change Rubrics, Version 1.0: A valid and equitable tool to measure transformation of life sciences departments at all institution types. CBE-Life Sciences Education, 15(4), ar60.

Bray Speth, E., Momsen, L. J., Moyerbrailean, G. A., Ebert-May, D., Long, T., ... \& Linton, D. (2010). 1, 2, 3, 4: Infusing quantitative literacy into introductory biology. CBE-Life Sciences Education, 9(3), 323-332.

Canning, E. A., Muenks, K., Green, D. J., \& Murphy, M. C. (2019). STEM faculty who believe ability is fixed have larger racial achievement gaps and inspire less student motivation in their classes. Science Advances, 5(2). eaau4734

Chen, X. (2016). Remedial coursetaking at U.S. Public 2- and 4-year institutions: Scope, experiences, and outcomes (NCES 2016-405). Washington, DC: National Center for Education Statistics. Retrieved November 11, 2018, from https://nces.ed.gov/pubs2016/2016405.pdf

Ching, C. C., \& Hursh, A. W. (2014). Peer modeling and innovation adoption among teachers in online professional development. Computers \& Education, 73, 72-82

Colon-Berlingeri, M., \& Burrowes, P. A. (2011). Teaching biology through statistics: Application of statistical methods in genetics and zoology courses. CBE-Life Sciences Education, 10, 259-267.

Community College Review. (2019). Accessed July 8, 2019, at www .communitycollegereview.com/

Cotner, S., \& Ballen, C. J. (2017). Can mixed assessment methods make biology classes more equitable?. PLoS ONE, 12(12), e0189610.

Denzin, N. K., \& Lincoln, Y. S. (Eds.). (2013). Collecting and interpreting qualitative methods (4th ed.). Los Angeles, CA: Sage.

Diegel, B. L. (2013). Perceptions of community college adjunct faculty and division chairpersons: Support, mentoring, and professional development to sustain academic quality. Community College Journal of Research and Practice, 37(8), 596-607.

Dolan, E. L. (2012). Next steps for Vision and Change: Moving from setting the vision to change. CBE-Life Sciences Education, 11(3), 201-202.

Dweck, C. S. (2006). Mindset. New York: Random House.

Eastwood, K. J., Boyle, M. J., Williams, B., \& Fairhall, R. (2011). Numeracy skills of nursing students. Nurse Education Today, 31, 815-818.

Ebert-May, D., Derting, T. L., Henkel, T. P., Middlemis Maher, J., Momsen, J. L., Arnold, B., \& Passmore, H. A. (2015). Breaking the cycle: Future faculty begin teaching with learner-centered strategies after professional development. CBE-Life Sciences Education, 14(2), ar22.
Edwards, A. R., Sandoval, C., \& McNamara, H. (2015). Designing for im provement in professional development for community college developmental mathematics faculty. Journal of Teacher Education, 66(5), $466-481$.

Emmel, N. (2013). Sampling and choosing cases in qualitative research: A realist approach. Washington, DC: Sage.

Feser, J., Vasaly, H., \& Herrera, J. (2013). On the edge of mathematics and biology integration: Improving quantitative skills in undergraduate biology education. CBE-Life Sciences Education, 12(2), 124-128.

Ford, D. Y., \& Grantham, T. C. (2003). Providing access for culturally diverse gifted students: From deficit to dynamic thinking. Theory into Practice, 42(3), 217-225

Gess-Newsome, J. (2015). A model of teacher professional knowledge and skill including PCK: Results of the thinking from the PCK Summit. In Berry, A., Friedrichsen, P., \& Loughran, J. (Eds.), Re-examining pedagogical content knowledge in science education (pp. 28-42). New York: Routledge.

Gess-Newsome, J., \& Lederman, N. G. (Eds.). (2001). Examining pedagogical content knowledge: The construct and its implications for science education (Vol. 6). Dordrecht, Netherlands: Kluwer Academic.

Goldstein, J., \& Flynn, D. F. B. (2011). Integrating active learning and quantitative skills into undergraduate introductory biology curricula. American Biology Teacher, 73(8), 454-461.

Gonzalez, B. (2016). Time for action: Vision and Change implementation in an online biology course at a community college. Journal of College Science Teaching, 45(4), 15

Hall, J. M., \& Ponton, M. K. (2005). Mathematics self-efficacy of college freshman. Journal of Developmental Education, 28(3), 26-32.

Henderson, C., Beach, A., \& Famiano, M. (2009). Promoting instructional change via co-teaching. American Journal of Physics, 77(3), 274-283.

Henderson, C., Beach, A., \& Finkelstein, N. (2011). Facilitating change in undergraduate STEM instructional practices: An analytic review of the literature. Journal of Research in Science Teaching, 48(8), 952-984.

Hester, S., Buxner, S., Elfring, L., \& Nagy, L. (2014). Integrating quantitative thinking into an introductory biology course improves students' mathematical reasoning in biological contexts. CBE-Life Sciences Education, $13,54-64$

Hoffman, K., Leupen, S., Dowell, K., Kephart, K., \& Leips, J. (2016). Development and assessment of modules to integrate quantitative skills in introductory biology courses. CBE-Life Sciences Education, 15(2), ar14.

Jameson, M. M., \& Fusco, B. R. (2014). Math anxiety, math self-concept, and math self-efficacy in adult learners compared to traditional undergraduate students. Adult Education Quarterly, 64(4), 306-322.

Jukes, L., \& Gilchrist, M. (2006). Concerns about numeracy skills of nursing students. Nurse Education in Practice, 6, 192-198.

Lo, S. M., Gardner, G. E., Reid, J., Napoleon-Fanis, V., Carroll, P., Smith, E., \& Sato, B. K. (2019). Prevailing questions and methodologies in biology education research: A longitudinal analysis of research in CBE-Life Sciences Education and at the Society for the Advancement of Biology Education Research. CBE-Life Sciences Education, 18(1), ar9.

Madlung, A., Bremer, M., Himelblau, E., \& Tullis, A. (2011). A study assessing the potential negative effects in interdisciplinary math-biology instruction. CBE-Life Sciences Education, 10, 43-54.

Mahaffey, E. (2002). The relevance of associate degree nursing education: Past, present, future. Online Journal of Issues in Nursing, 7(2), manuscript 2.

Marshall, J. A., \& Durán, P. (2018). Are biologists getting the mathematical training they need in college? Biochemistry and Molecular Biology Education, 46(6), 612-618.

Marsteller, P., de Pillis, L., Findley, A., Joplin, K., Pelesko, J., Nelson, K., ... Watkins, J. (2010). Toward integration: From quantitative biology to math bio-biomath? CBE-Life Sciences Education, 9(3), 165-171.

McFarland, J., Hussar, B., Wang, X., Zhang, J., Wang, K., Rathbun, A., .. \& Bullock Mann, F. (2018). The condition of education 2018 (NCES 2018-144). Washington, DC: National Center for Education Statistics. Retrieved November 8, 2018, from https://nces.ed.gov/pubsearch/ pubsinfo.asp?pubid=2018144

Miller, S., \& Tanner, K. D. (2015). A portal into biology education: An annotated list of commonly encountered terms. CBE-Life Sciences Education, $14(2), \mathrm{fe} 2$. 
National Research Council. (2003). BIO2010: Transforming undergraduate education for future research biologists. Washington, DC: National Academies Press.

National Research Council and National Academy of Engineering. (2012) Community colleges in the evolving STEM education landscape: Summary of a summit. Washington, DC: National Academies Press.

National Science Board. (2018). Science and engineering indicators 2018 (NSB-2018-1). Alexandria VA: National Science Foundation. Retrieved July 8, 2019, from www.nsf.gov/statistics/2018/nsb20181/report/sections/ higher-education-in-science-and-engineering/undergraduate-education -enrollment-and-degrees-in-the-united-states

Nunley, C. R., Bers, T. H., \& Manning, T. (2011). Learning outcomes assessment in community colleges (Occasional Paper 10). Champaign, IL: National Institute for Learning Outcomes Assessment. Retrieved November 12, 2018, from www.learningoutcomesassessment.org/documents/ OccasionalPaperTen.pdf

Olimpo, J. T., Pevey, R. S., \& McCabe, T. M. (2018). Incorporating an interactive statistics workshop into an introductory biology course-based undergraduate research experience (CURE) enhances students' statistical reasoning and quantitative literacy skills. Journal of Microbiology $\&$ Biology Education, 19(1), 1-7.

Pajares, F., \& Miller, M. D. (1994). Role of self-efficacy and self-concept beliefs in mathematical problem solving: A path analysis. Journal of Educational Psychology, 86(2), 193-203.

Park, S., \& Oliver, J. S. (2008). Revisiting the conceptualisation of pedagogical content knowledge (PCK): PCK as a conceptual tool to understand teachers as professionals. Research in Science Education, 38(3), 261-284.

Paulson, K., \& Boeke, M. (2006). Adult learners in the United States: A national profile. Washington, DC: American Council on Education.

Penuel, W. R., Sun, M., Frank, K. A., \& Gallagher, H. A. (2012). Using social network analysis to study how collegial interactions can augment teacher learning from external professional development. American Journal of Education, 119(1), 103-136.

Peteroy-Kelly, M., Brancaccio-Taras, L., Awong-Taylor, J., Balser, T., Jack, T. Lindsay, S., ... \& Pape-Lindstrom, P. (2019). A qualitative analysis to identify the elements that support department level change in the life sciences: The PULSE Vision \& Change Recognition Program. PLOS ONE, 14(5), e0217088.
Ross-Gordon, J. M. (2003). Adult learners in the classroom. New Directions for Student Services, 2003(102), 43-52.

Saldaña, J. (2016). The coding manual for qualitative researchers. Thousand Oaks, CA: Sage.

Schinske, J. N., Balke, V. L., Bangera, M. G., Bonney, K. M., Brownell, S. E. Carter, R. S., ... \& Corwin, L. C. (2017). Broadening participation in biology education research: Engaging community college students and faculty. CBE-Life Sciences Education, 16(2), $\mathrm{mr} 1$

Shulman, L. S. (1986). Those who understand: Knowledge growth in training Educational Researcher, 15(2), 4-14.

Sloan, A., \& Bowe, B. (2014). Phenomenology and hermeneutic phenomenology: The philosophy, the methodologies, and using hermeneutic phenomenology to investigate lecturers' experiences of curriculum design. Quality \& Quantity, 48(3), 1291-1303.

Smit, R. (2012). Towards a clearer understanding of student disadvantage in higher education: Problematizing deficit thinking. Higher Education Research \& Development, 31(3), 369-380.

Thompson, K. V., Nelson, K. C., Marbach-Ad, G., Keller, M., \& Fagan, W. F. (2010). Online interactive teaching modules enhance quantitative proficiency of introductory biology students. CBE-Life Sciences Education, 9, 277-283

U.S. Department of Education, Office of Planning, Evaluation and Policy Development, Policy and Program Studies Service. (2014). National assessment of career and technical education: Final report to Congress. Washington, DC. Retrieved July 8, 2018, from www2.ed.gov/rschstat/ eval/sectech/nacte/career-technical-education/final-report.pdf

Van Driel, J. H., \& Berry, A. (2012). Teacher professional development focusing on pedagogical content knowledge. Educational Researcher, 41(1), $26-28$.

Zagallo, P., Meddleton, S., \& Bolger, M. S. (2016). Teaching real data interpretation with models (TRIM): Analysis of student dialogue in a large-enrollment cell and developmental biology course. CBE-Life Sciences Education, 15(2), ar17.

Zhang, J., \& Oymak, C. (2018). Participants in subbaccalaureate occupational education: 2012. Washington, DC: National Center for Education Statistics, Institute of Education Sciences. Retrieved July 8, 2019, from https://nces.ed.gov/pubs2018/2018149.pdf 